\title{
Mechanistic Principles of Ion Transport in the Na,K-ATPase
}

\author{
Hans-Jürgen Apell \\ Department of Biology, University of Konstanz, Konstanz 78464, Germany \\ e-mail:h-j.apell@uni-konstanz.de
}

\begin{abstract}
The Na,K-ATPase is a member of the P-type ATPase family and a primary active ion transporter for $\mathrm{Na}^{+}$and $\mathrm{K}^{+}$ions in the cytoplasmic membrane of virtually all animal cells. Considerable progress in understanding the ion-pump mechanism of the $\mathrm{Na}, \mathrm{K}-\mathrm{ATPase}$ was gained by combining biophysical and biochemical studies of more than 30 years with structural information at atomic resolution available since recent years. Biophysical studies have revealed detailed properties of the ion movements that led to a gated-channel model which is strongly supported by structural findings obtained for the sodium pump. The basic question how the free Gibbs energy released by ATP hydrolysis is transferred to the protein and transformed into uphill transport of the ions is still without reply.
\end{abstract}

Keywords: active ion transport, P-type ATPase, structure-function relation, kinetics, ion binding, transport mechanism, energetics

\section{INTRODUCTION}

In the animal kingdom, sodium and potassium ion gradients across the cell membrane are a prerequisite for life. The potassium-ion concentration is inside the cell higher and controls preferentially the electrical membrane potential, which is always negative inside. The sodium-ion gradient is conversely oriented and a powerful source of free energy to fuel numerous sodium-coupled transport proteins which facilitate transport of amino acids or sugars, to name a few examples. To keep the cells alive it is therefore crucial that the potassium reservoir in the cytoplasm is continuously replenished, the sodium concentration kept low, and someone has to provide the energy to accomplish this. The primary actor in this game is known since 1957: the Na,K-ATPase or sodium pump. This protein was discovered by Jens C. Skou, and he identified its basic properties and functions [1]. This contribution earned him the Nobel prize in 1997 [2].

The Na,K-ATPase is a housekeeping enzyme in virtually all animal cells. It consists of two, and in some tissues of three subunits. The $\alpha$ subunit has a molar mass of about $100 \mathrm{k}$ Dalton and carries out all enzymatic and transport functions. The enzymatic function is localized in the cytoplasmic part of this subunit, to which ATP binds as ATP-magnesium complex to the nucleotide-binding site, similar to all P-type ATPases [3]. This cytoplasmic part of the protein is formed by the N, P, and A domain and contains about $50 \%$ of the amino acids of the subunit. In due course of the pump cycle the $\gamma$ phosphate of the bound ATP at the N domain is transferred to the phosphorylation site at the P domain, and thus the free energy of ATP hydrolysis is made available to energize ion transport uphill the electrochemical potential gradient across the membrane. Both other subunits, $\beta$ and FXYD, contribute to correct membrane integration, folding of the $\alpha$ subunit, ensure a correct trafficking to the cytoplasmic membrane, and account in a regulatory manner for the variable physiological needs of $\mathrm{Na}, \mathrm{K}-\mathrm{ATPase}$ activity in different tissues [4]. The regulatory FXYD subunit is tissue specific and not expressed in all cells $[5,6]$.

Under physiological conditions the stoichiometry is a movement of $3 \mathrm{Na}^{+}$out of and $2 \mathrm{~K}^{+}$into the cytoplasm per molecule ATP hydrolyzed. At typical concentration ratios across the cytoplasmic membrane, $c_{\mathrm{Na}^{+}, \mathrm{cyt}} / c_{\mathrm{Na}^{+} \text {, ext }} \approx 0.1$ and $c_{\mathrm{K}^{+}, \mathrm{cyt}} / c_{\mathrm{K}^{+}, \text {ext }} \approx 30$, and a membrane potential of $-70 \mathrm{mV}$, a free energy of $38 \mathrm{~kJ} / \mathrm{mol}$ is necessary to transport $3 \mathrm{~mol} \mathrm{Na}^{+}$and $4 \mathrm{~kJ} / \mathrm{mol}$ to transport $2 \mathrm{~mol} \mathrm{~K}{ }^{+}$. The energy available from ATP hydrolysis is about $58 \mathrm{~kJ} / \mathrm{mol}$ so that a representative efficiency of the ion pump is in the order of $70 \%$.

A characteristic property of the $\mathrm{Na}, \mathrm{K}$-ATPase is its inhibition by cardiotonic steroids, e.g. ouabain, which bind from the outside of the protein to a conserved specific moiety [7], that is the binding site of endogenous ouabain, a regulatory steroid hormone [8]. 


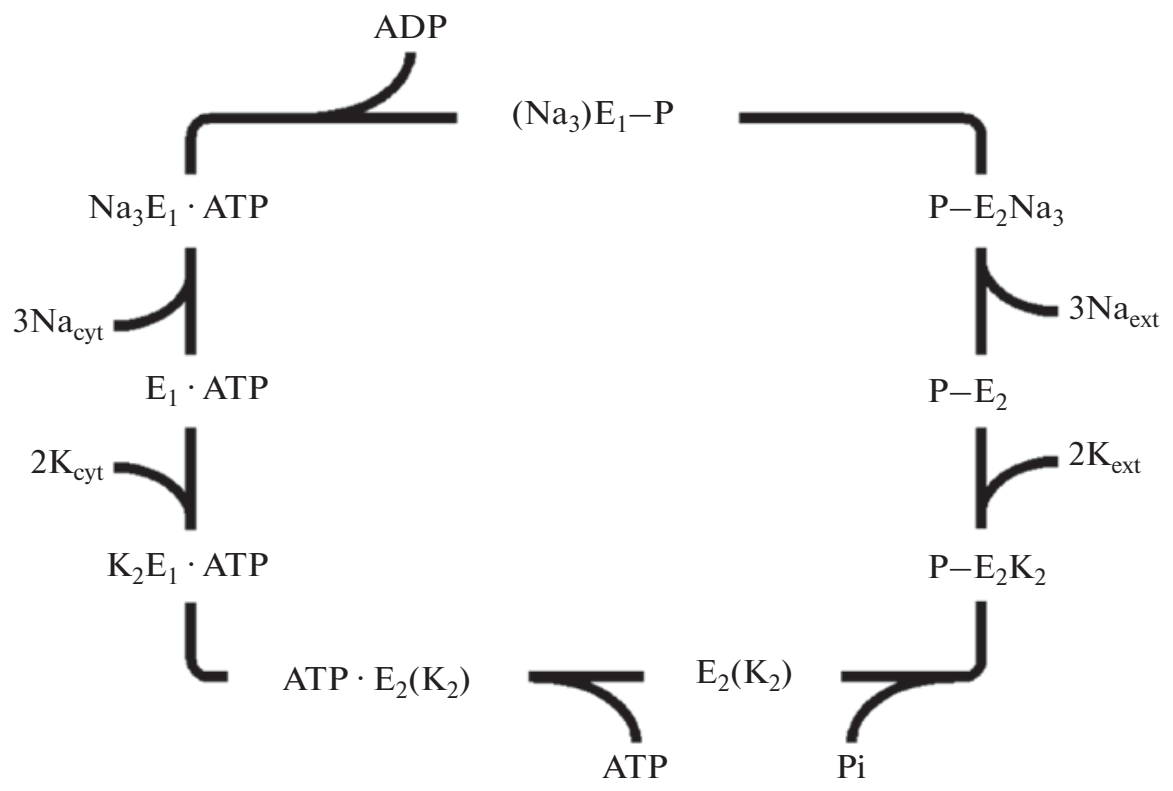

Fig. 1. The Post-Albers scheme describes the pump cycle of the Na,K-ATPase under physiological conditions. Sodium and potassium ion transport is performed in the so-called Ping-Pong mode. In the $\mathrm{E}_{1}$ conformation the ion-binding sites are accessible to the cytoplasm and allow exchange of two $\mathrm{K}^{+}$ions against three $\mathrm{Na}^{+}$ions. In the $\mathrm{E}_{2}$ conformation the reverse exchange is performed with the extracellular medium. In the "occluded" states, $\left(\mathrm{Na}_{3}\right) \mathrm{E}_{1}-\mathrm{P}, \mathrm{E}_{2}(\mathrm{~K})_{2}$, and ATP $\cdot \mathrm{E}_{2}(\mathrm{~K})_{2}$, the bound ions are trapped inside the membrane domain, unable to exchange with the aqueous phases. The upper half cycle is ATP driven and transports exclusively $\mathrm{Na}^{+}$ions. The lower half cycle is dependent on enzyme dephosphorylation and works (under unphysiological conditions) also with congeners of $\mathrm{K}^{+}$ions, such as $\mathrm{Rb}^{+}, \mathrm{Tl}^{+}, \mathrm{NH}_{4}^{+}, \mathrm{H}^{+}$or even $\mathrm{Na}^{+}$.

The biochemical analysis of enzymatic activity and transport function led to the proposal of a cyclic reaction sequence of the $\mathrm{Na}, \mathrm{K}-\mathrm{ATPase}$ which was introduced as the so-called Post-Albers cycle $[9,10]$ more than forty years ago (Fig. 1). The main feature of this pump cycle is that there are two principal conformations in which the ion-binding sites are accessible either from cytoplasm $\left(E_{1}\right)$ or the extracellular side $\left(\mathrm{P}-\mathrm{E}_{2}\right)$. Between both access modes so-called occluded states are intercalated, $\left(\mathrm{Na}_{3}\right) \mathrm{E}_{1}-\mathrm{P}, \mathrm{E}_{2}\left(\mathrm{~K}_{2}\right)$, and ATP $\cdot \mathrm{E}_{2}\left(\mathrm{~K}_{2}\right)$, which prevent simultaneous access to the ion sites from both aqueous phases, and therefore, excludes an electric short circuit across the cell membrane. A second characteristic feature is the Ping-Pong mode of the Na,K-ATPase which represents a consecutive transport of $\mathrm{Na}^{+}$and $\mathrm{K}^{+}$, each by one half of the pump cycle. The same binding sites are used for both ion species.

The Post-Albers scheme was found to be a general mechanism valid also for all other P-type ATPases whose pump cycles were studied so far, such as the $\mathrm{Ca}$ ATPase of the sarcoplasmic reticulum (SERCA) and the gastric $\mathrm{H}, \mathrm{K}$-ATPase [11], as well as the KdpFABC ATPase [12]. P-type ATPases share an (eponymous) phosphorylated intermediate in which the $\gamma$ phosphate of the ATP molecule is transferred to a highly conserved aspartate located at the P domain of the protein (see below). P-type ATPases transport various cations and even phospholipids, they do not only have a common pump mechanism but also show comprehensive structural similarities [13].

\section{BIOPHYSICAL METHODS OF FUNCTIONAL ANALYSIS}

According to the stoichiometry of the $\mathrm{Na}, \mathrm{K}$ ATPase one positive electric charge is removed from the cytoplasm per ATP molecule hydrolyzed, and this property, which is called electrogenicity [14], turned out to be an important attribute exploited for detailed investigations of the ion-transport mechanism. An electrogenic ion transporter acts as current generator and contributes to the membrane potential by moving ions through the membrane dielectric [14]. Since ion transport by the Na,K-ATPase can be divided into several partial reactions according to the Post-Albers cycle (Fig. 1), experimental techniques had to be developed and applied to identify the charge-translocating steps, as well as to detect which amount of charge is moved how far and how fast while the pump process proceeds. A systematic theoretical approach to obtain a manageable representation of the pump process led to the introduction of dielectric coefficients which quantify the fraction of the transmembrane voltage drop which the ions traverse in each individual step $[15,16]$. These parameters together with mea- 
sured rate constants or equilibrium dissociation constants allow a quantitative description of the transport process and, in consequence, modelling of the pump mechanism.

Based on a theoretical approach introduced by T.L. Hill [17], in which the concept of basic free energies is used to calculate the amount of free energy needed or dissipated in each reaction step of the pump cycle, an appropriate analysis can be performed for the $\mathrm{Na}, \mathrm{K}$-ATPase [14]. Using the experimental results obtained from a detailed kinetic analysis in our laboratory [18] the energy balance has been calculated under conditions close to the physiological situation (Fig. 2). The difference between the energy levels of two neighboring states provides information about the energy gained or spent. The determination of these differences from experimental kinetic parameters is described on pages 19-25 of Ref. [14]. Downward steps represent energy dissipation, steps up energy consumption. Small energy changes indicate processes close to thermodynamic equilibrium. The striking results are that both processes, $\mathrm{Na}^{+}$binding and release, occur close to thermodynamic equilibrium, while $\mathrm{K}^{+}$binding and release are the processes with the highest energy dissipation and requirement, respectively. Surprisingly, the phosphorylation and dephosphorylation as well as the conformation transitions are rather unobtrusive and don't contain any power-stroke like behavior as it would be expected from macroscopic machines.

The $\mathrm{Na}^{+}$transporting half of the Post-Albers cycle was investigated with purified, flat membrane fragments which contain the Na,K-ATPase in a high density as only protein species with a purity of about $99 \%$. Such membrane fragments can be coupled capacitively to planar lipid bilayers or solid supported membranes. The advantage of this method is that pump currents don't have to be separated from other simultaneous current components through the membrane. However, the ion composition of the extracellular side of the membrane, which is in contact with the adsorbing membrane, cannot be easily controlled. Nevertheless, the results the currents detected with both assays were in fair agreement when corresponding experiments are compared and both methods are complementary in a fruitful manner otherwise.

Numerous detailed kinetic studies of the $\mathrm{Na}^{+}$ transport with open membrane fragments adsorbed to planar lipid bilayer are reported [19-23]. The fragments align by implication with the extracellular side to the bilayer surface and establish a tight capacitive coupling. This condition allows the detection of transient currents by the electrodes on either sides of the lipid bilayer upon triggering charge movements in the compound membrane system (Fig. 3), and subsequent determination of the causative electrogenic events in the ion pumps [24, 25]. The advantage of this method is that the only ion-transporting protein in this prepa-

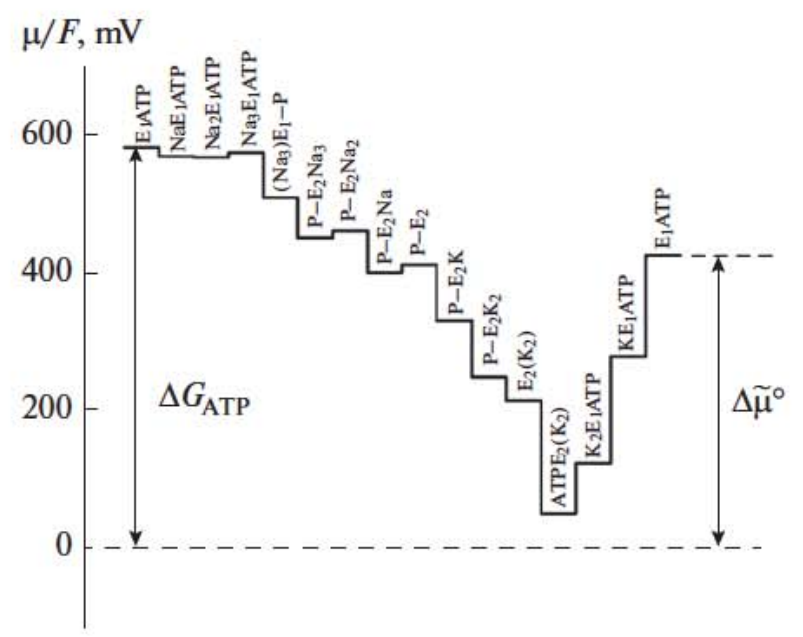

Fig. 2. Free energy levels of the individual states of the pump cycle of the Na,K-ATPase. The energy levels were calculated according to the theory of basic free energies [14] under the (near physiologic) conditions of $\left[\mathrm{Na}^{+}\right]_{\mathrm{cyt}}=$ $5 \mathrm{mM},\left[\mathrm{K}^{+}\right]_{\mathrm{cyt}}=150 \mathrm{mM},\left[\mathrm{Na}^{+}\right]_{\mathrm{ext}}=140 \mathrm{mM},\left[\mathrm{K}^{+}\right]_{\mathrm{ext}}=$ $5 \mathrm{mM},[\mathrm{ATP}]=5 \mathrm{mM},[\mathrm{ADP}]=0.1 \mathrm{mM},\left[\mathrm{P}_{\mathrm{i}}\right]=5 \mathrm{mM}$, $T=20^{\circ} \mathrm{C}$, and $V_{\mathrm{m}}=0$. The corresponding kinetic parameters were taken from a published study [18]. The basic free energy values, $\mu$, plotted on the $Y$ axis, have been divided by the Faraday constant, $F$, to display them in mV. $\Delta G_{\text {ATP }}$ is the free energy of ATP hydrolysis that is available in the

enzyme-ATP complex before hydrolysis, $\Delta \tilde{\mu}^{0}$ is the electrochemical work performed by the $\mathrm{Na}, \mathrm{K}$-ATPase which is stored across the cytoplasmic membrane after comple-

tion of the pump cycle. The yield, $\Delta \tilde{\mu}^{0} / \Delta G_{\mathrm{ATP}}$, is in the order of $70 \%$.

ration is the $\mathrm{Na}, \mathrm{K}$-ATPase [26]. In the presence of the $\mathrm{Na}, \mathrm{K}-\mathrm{ATPase}$-specific inhibitor ouabain no significant other current components are measured. The ion-pump process can be initiated elegantly by producing an ATP-concentration jump when the energizing substrate is released from the inactive precursor "caged ATP" [27] by an UV-light flash, and binds simultaneously to the nucleotide binding site of all enzyme molecules. A recent advancement of the method is the application of solid supported membranes. Instead of the fragile lipid bilayer a solid, surface-modified gold electrode is used to adsorb membrane fragments [28-30]. In such a setup rapid solution exchange allows also concentration jumps of substrates of which no caged compounds exist, such as the transported ions, $\mathrm{Na}^{+}$and $\mathrm{K}^{+}$. The time course of the current transients upon an ATP-concentration jump (Fig. 3) can be fitted by the sum of three exponential functions, and the substrate dependence of the resulting time constants allows their assignment to the rate-limiting steps of the activated partial reactions in the Post-Albers cycle. To analyze especially the minor charge movements occurring with cytoplasmic $\mathrm{Na}^{+}$binding, a charge-pulse technique was developed 


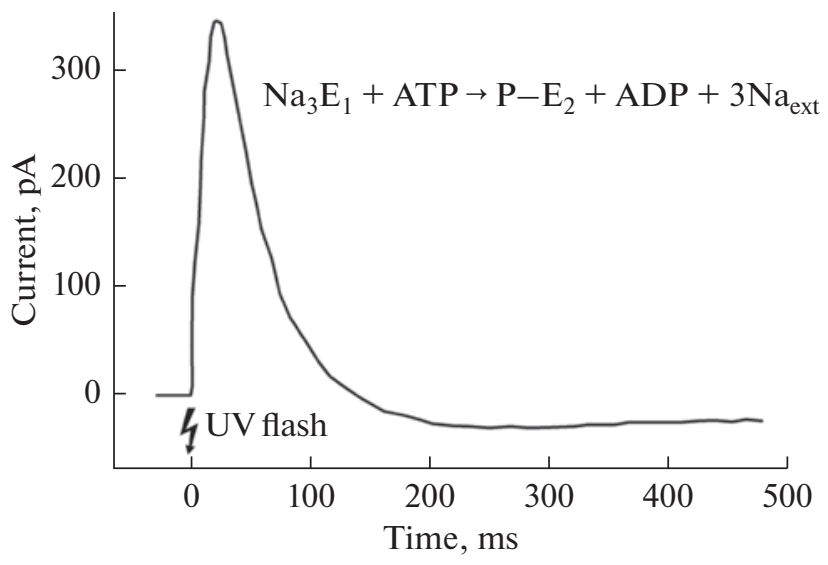

Fig. 3. Current transient generated by the Na,K-ATPase in the absence of $\mathrm{K}^{+}$after a $40 \mu \mathrm{S} \mathrm{UV}$ flash given at time $t=0$ to release ATP from its inert caged precursor. The aqueous solutions contained $150 \mathrm{mM} \mathrm{NaC1}, 50 \mathrm{mM}$ Tris chloride, $\mathrm{pH} 7.0,20 \mathrm{mM}$ dithiothreitol and $2 \mathrm{mM} \mathrm{MgCl}$. The temperature was $20^{\circ} \mathrm{C}$. $0.5 \mathrm{mM}$ caged ATP and $40 \mu \mathrm{g} / \mathrm{mL}$ $\mathrm{Na}, \mathrm{K}$-ATPase in the form of membrane fragments were added on one side of the membrane cuvette to adsorb to lipid bilayer over a period of $20 \mathrm{~min}$ prior to the flash experiment. The positive sign of the current corresponds to a translocation of positive charge in the membrane fragment towards the black lipid membrane. The area of the membrane was $0.64 \mathrm{~mm}^{2}$.

[31] and an admittance-measurement technique was introduced [32].

A second approach to study transport kinetics is the use of fluorescence techniques [11]. Intrinsic tryptophan fluorescence was used to study conformational rearrangements in the course of the Post-Albers cycle [33], but mainly extrinsic voltage-dependent fluorescent dyes were applied to study pump function. In a first step of development, $\mathrm{Na}, \mathrm{K}$-ATPase was solubilized, reconstituted in lipid vesicles and the overall pump current was determined by so-called slow fluorescence dyes such as oxonol VI [34-37] that responds to the net charge translocation by the $\mathrm{Na}, \mathrm{K}$-ATPase. Major progress was made when fast electrochromic styryl dyes were introduced which are able to resolve charge movements in the membrane domain of the $\mathrm{Na}, \mathrm{K}-\mathrm{ATPase}[18,38,39]$. In combination with fast relaxation techniques, such as the use of caged compounds or stopped-flow techniques, a wealth of data was gained that contain functional information and provided new mechanistic insights. Electrochromic styryl dyes were originally introduced to detect fast changes of membrane potential in neurons. The same dyes could, however, also be used to detect changes of the local electric fields in the membrane preparations containing P-type ATPases [40]. Styryl dyes have a high partition coefficient in favor of the membrane, insert in a defined orientation and respond by an absorbance shift when the electric field in the membrane chances $[39,40]$.

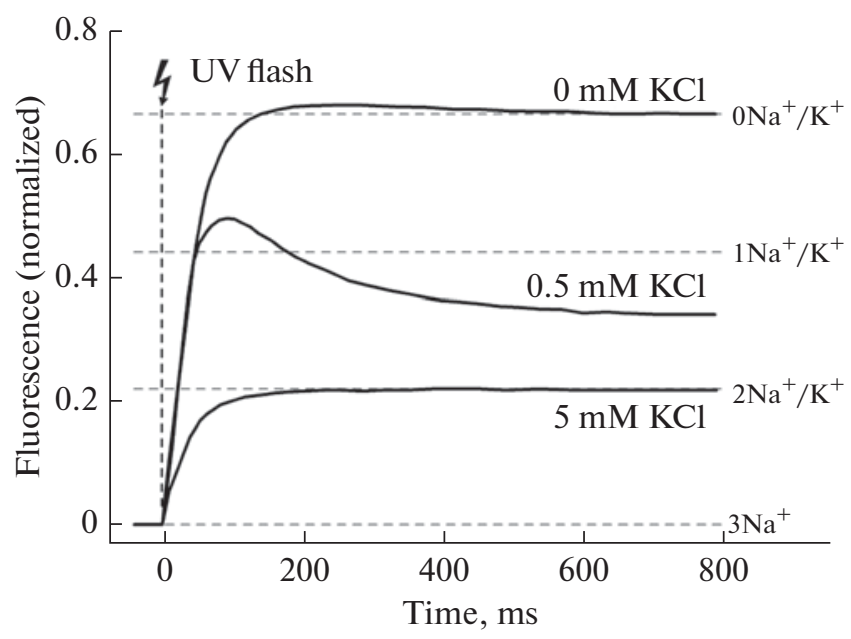

Fig. 4. Time course of fluorescence changes of the electrogenic styryl dye RH421. Soluble membrane fragments containing $\mathrm{Na}$,K-ATPase in a high density were equilibrated in a buffer solution containing $150 \mathrm{mM} \mathrm{NaCl}$, $25 \mathrm{mM}$ histidine, $0.5 \mathrm{mM}$ EDTA, $10 \mathrm{mM} \mathrm{MgCl}_{2}$, and $20 \mu \mathrm{M}$ caged ATP. At time 0 , ATP was released by a UV flash from the inert precursor caged ATP. Experiments were repeated in the presence of the indicated concentrations of $\mathrm{KCl}$. At the chosen initial conditions (no ATP) the pumps are arrested in the state $\mathrm{Na}_{3} \mathrm{E}_{1}$. The fluorescence changes were normalized with respect to the fluorescence level prior the release of ATP $(t<0)$. The average steady state obtained after the release of ATP depends on the $\mathrm{K}^{+}$ concentration and varies between $\mathrm{P}-\mathrm{E}_{2}\left(\right.$ at $0 \mathrm{~K}^{+}$) and $\mathrm{P}-\mathrm{E}_{2} \mathrm{~K}_{2}\left(\right.$ at $5 \mathrm{mM} \mathrm{K}^{+}$). Since the fluorescence of RH421 is linearly dependent on the amount of ions bound in the $\mathrm{Na}, \mathrm{K}-\mathrm{ATPase}$, the dashed grey lines could be drawn to indicate the average number of ions bound.

The detected fluorescence levels are proportional to the amount of charge in the membrane domain of the ion pumps. The fluorescence level is linearly dependent on the amount of charge in the membrane domain and thus contains information on the number of ions in the binding sites of the ion pumps. The time course of the fluorescence signal reports information on the rate constants controlling the partial reactions performed by the Na,K-ATPase. In Fig. 4 the fluorescence response is shown upon an ATP-concentration jump experiment in the presence of saturating $\mathrm{NaCl}$ concentration and the indicated $\mathrm{KCl}$ concentrations. Upon a UV-light flash the ATP concentration is raised in a stepwise fashion from 0 to $20 \mu \mathrm{M}$. In the absence of $\mathrm{KCl}$ the ATP-induced partial reaction with initially three $\mathrm{Na}^{+}$ions bound leads to the $\mathrm{P}-\mathrm{E}_{2}$ state in which all three ions are released to the extracellular side. In the presence of saturating $\mathrm{KCl}(5 \mathrm{mM})$ the final state is one with $2 \mathrm{~K}^{+}$bound, $\mathrm{E}_{2}\left(\mathrm{~K}_{2}\right)$. The corresponding steady-state fluorescence levels are shown in Fig. 4. This technique provides an easy access to determine the electrogenic reaction steps in the pump cycle and to measure ion-binding affinities of the binding sites 
for the $\mathrm{Na}, \mathrm{K}-\mathrm{ATPa}$ e [41], SERCA [42], gastric $\mathrm{H}, \mathrm{K}$-ATPase [43] and the KdpFABC ATPase from E.coli [12].

\section{ESSENTIAL EXPERIMENTAL FINDINGS}

Going around the pump cycle (Fig. 1) the transport properties of the Na,K-ATPase will be discussed on the basis of results obtained from experiments performed with the techniques described above:

$\mathrm{K}_{2} \mathrm{E}_{1} \cdot \mathrm{ATP} \rightarrow \mathrm{E}_{1} \cdot \mathbf{A T P} \rightarrow \mathrm{Na}_{3} \mathrm{E}_{1} \cdot \mathbf{A T P}:$ In the $\mathrm{E}_{1}$ conformation the two $\mathrm{K}^{+}$ions imported from the extracellular solution are exchanged against three $\mathrm{Na}^{+}$ ions. The observation that $\mathrm{K}^{+}$release and binding of the first two $\mathrm{Na}^{+}$ions is not electrogenic $[44,45]$ was initially interpreted as indication for a location of negatively charged binding sites close to the cytoplasmic surface in a wide, water filled vestibule. This electroneutrality turned out, however, to be only an apparent effect [41]. In the $\mathrm{E}_{1}$ conformation the affinity of the binding sites for protons is so high that at physiological $\mathrm{pH}$ and in the absence of $\mathrm{Na}^{+}$and $\mathrm{K}^{+}$the sites are mostly protonated. Therefore, binding of both $\mathrm{K}^{+}$ions and the first two $\mathrm{Na}^{+}$ions in titration experiments is an electroneutral exchange against protons. At unphysiologically high $\mathrm{pH}$ electrogenicity of $\mathrm{K}^{+}$and $\mathrm{Na}^{+}$binding becomes very well visible when beginning with a cation-free electrolyte [41]. Binding or exchange of $\mathrm{K}^{+}$and $\mathrm{Na}^{+}\left(\right.$or $\left.\mathrm{H}^{+}\right)$in this reaction sequence is diffusion-controlled and thus significantly faster than the subsequent phosphorylation reaction. Therefore, the distribution of the occupation of all states in the reaction sequence between $\mathrm{K}_{2} \mathrm{E}_{1} \cdot \mathrm{ATP}$ and $\mathrm{Na}_{3} \mathrm{E}_{1} \cdot \mathrm{ATP}$ can be assumed to be in a quasi-equilibrium under physiological conditions. The exchange of ions between $\mathrm{K}_{2} \mathrm{E}_{1} \cdot$ ATP and $\mathrm{Na}_{2} \mathrm{E}_{1} \cdot \mathrm{ATP}$ in the reaction sequence of the Post-Albers cycle is conducted without significant detectable net charge movements inside the membrane domain.

Under physiological conditions in which the cytoplasmic $\mathrm{K}^{+}$concentration is high and the $\mathrm{Na}^{+}$low, most of the enzyme in the $E_{1}$ state is present in $\mathrm{K}_{2} \mathrm{E}_{1} \cdot$ ATP [46] and only a minor fraction in $\mathrm{Na}_{3} \mathrm{E}_{1} \cdot$ ATP, the state which is capable of being phosphorylated. The fact that this unfavorable displacement is not completely antagonistic to pump function has to be assigned to the fact that the exchange of ions in the binding sites is so fast (diffusion controlled) that the drain of the $\mathrm{Na}_{3} \mathrm{E}_{1} \cdot \mathrm{ATP}$ state by phosphorylation is instantaneously compensated. Nevertheless, it is known that the Na pumps run way below their kinetically possible maximum turnover due to this limiting condition.

Binding of a $\mathrm{Na}^{+}$ion to the third and exclusively $\mathrm{Na}^{+}$-specific site in the $\mathrm{E}_{1}$ state was found to be electrogenic and the dielectric coefficient was shown to be

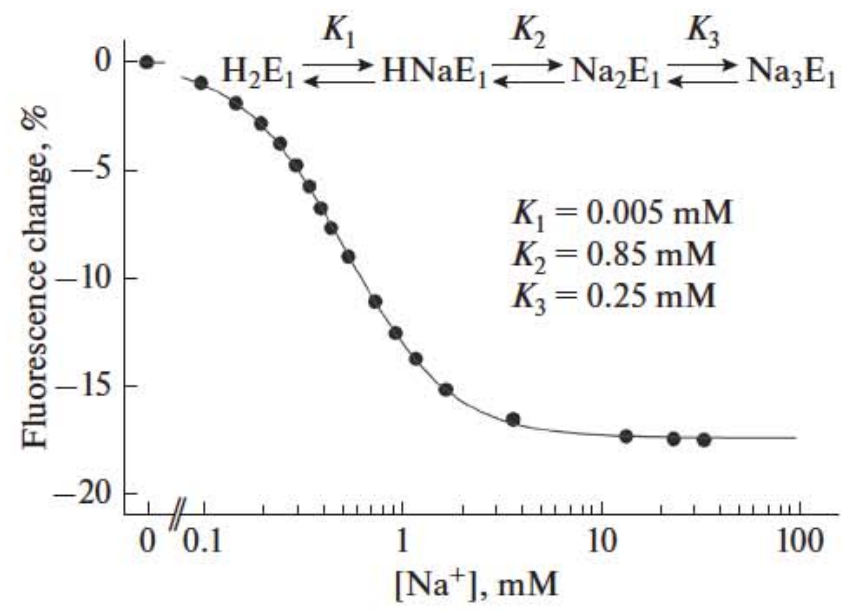

Fig. 5. Electrogenic binding of $\mathrm{Na}^{+}$ions in the $\mathrm{E}_{1}$ conformation of the Na,K-ATPase detected by the electrochromic styryl dye RH421. The presented data are the average of more than 40 titration experiments at $\mathrm{pH} 7.2$ and in the absence of $\mathrm{Mg}^{2+}$. Error bars are smaller than the size of the data points. The concentration dependence was fitted by the mathematical representation of the inserted reaction sequence. The least squares fit resulted in equilibrium dissociation constants for $\mathrm{Na}^{+}$of $\mathrm{K}_{1}=0.005 \mathrm{mM}$ (values < $0.01 \mathrm{mM}$ were indistinguishable), $\mathrm{K}_{2}=0.85 \pm 0.12 \mathrm{mM}$, $\mathrm{K}_{3}=0.25 \pm 0.07 \mathrm{mM}$.

in the order of 0.25 [31, 32]. It has been demonstrated that electrogenic binding of the third $\mathrm{Na}^{+}$as detected by the styryl dye RH421 and by directly measured charge movement are identical [28]. This means that $\mathrm{Na}^{+}$traverses $25 \%$ of the electric-potential drop across membrane to reach its binding site from the cytoplasm. (This does not necessarily mean that the spatial distance is also $25 \%$ of the membrane thickness [14].) Study of cytoplasmic $\mathrm{Na}^{+}$binding and detailed analysis of the binding affinities revealed that the third $\mathrm{Na}^{+}$ binds to a site with a higher affinity for $\mathrm{Na}^{+}$than the second (Fig. 5). Such an observation can be explained by the assumption that the third binding site becomes available only after the first two sites are already occupied by $\mathrm{Na}^{+}$[46]. A possible mechanism is a conformational rearrangement in the transmembrane helices of the membrane domain upon binding of the second $\mathrm{Na}^{+}$which then assembles the third $\mathrm{Na}^{+}$site (or the access to it). In case of SERCA it was shown that the whole sequence of proton release and the corresponding subsequent $\mathrm{Ca}^{2+}$ binding in the $\mathrm{E}_{1}$ conformation is an alternating succession of conformational relaxation and single-ion release/binding steps [42, 47], a mechanism which may be expected to be similar in the case of the $\mathrm{Na}, \mathrm{K}-\mathrm{AT}$ Pase.

When binding of the third $\mathrm{Na}^{+}$was measured with the fluorescence of the conformation-sensitive label fluorescein isothiocyanate (FITC) [45], which is linked to a highly conserved lysine in the nucleotide- 
binding site, significant concurrent changes were observed simultaneously with the binding in the membrane domain. Only binding of the third sodium triggers a rearrangement of the cytoplasmic domain of the $\mathrm{Na}, \mathrm{K}-\mathrm{ATPase}$ and sort of arms the protein to make way for enzyme phosphorylation by the ATP already bound to its binding site.

$\mathrm{Na}_{3} \mathbf{E}_{1} \cdot \mathbf{A T P} \rightarrow\left(\mathrm{Na}_{3}\right) \mathrm{E}_{1}-\mathbf{P} \rightarrow \mathrm{P}-\mathrm{E}_{2} \mathrm{Na}_{3}$ : When the $\mathrm{Na}, \mathrm{K}-\mathrm{ATPase}$ is phosphorylated by ATP the ionbinding sites are occluded concomitantly, according to the Post-Albers cycle (Fig. 1). For this reaction step no charge movements could be detected [19] which indicates that the three ions in their binding sites are not moved (at least perpendicular to the membrane plane). The occluded state, $\left(\mathrm{Na}_{3}\right) \mathrm{E}_{1}-\mathrm{P}$, is transient and spontaneously followed by a conformation transition into the $\mathrm{P}-\mathrm{E}_{2}$ conformation with deoccluding ion binding sites. This step is the rate-limiting process in the $\mathrm{Na}^{+}$-translocating half cycle $[18,22,31,48]$. The conformation transition shows only a minor dielectric coefficient $(0-0.1)$ [31], and it cannot be discriminated whether this is caused by ion movements or movements of charged side chains in the helices of the membrane domain which undergo considerable reorientations during the transition. Besides unclasping the access between binding sites and extracellular aqueous phase another major functional consequence of the transition is the reduction of the binding affinity for $\mathrm{Na}^{+}$by a factor of about 500 [18].

$\mathbf{P}-\mathbf{E}_{2} \mathbf{N a}_{3} \rightarrow \mathbf{P}-\mathbf{E}_{2}$ : Extracellular sodium release is the best investigated partial reaction of the $\mathrm{Na}, \mathrm{K}$ ATPase pump cycle [18, 31, 48-52]. It was found that the three $\mathrm{Na}^{+}$ions are released sequentially and that there is a defined order as deduced from the different electrogenic and kinetic properties which allow an assignment to the respective steps. The first $\mathrm{Na}^{+}$ released has the highest dielectric coefficient of the whole pump cycle. The ion traverses $65-70 \%$ of the electric potential in the membrane and its release process has the slowest rate constant of the three ions in the order of $1000 \mathrm{~s}^{-1}$. The activation energy of this partial reaction was found to be about $80 \mathrm{~kJ} / \mathrm{mol}$ [53]. Dissociation of an ion from its binding site and diffusion through a narrow pore-like structure have activation energies of below $20 \mathrm{~kJ} / \mathrm{mol}$. Therefore, the high activation energy indicates that conformational rearrangements of the membrane domain are involved. The commonly accepted mechanism is a rate-limiting deocclusion process for the first ion as immediate consequence of the conformation transition from $\mathrm{E}_{1}-\mathrm{P}$ to $\mathrm{P}-\mathrm{E}_{2}$. Both subsequent steps, dissociation of $\mathrm{Na}^{+}$and diffusion from the binding site to the external aqueous phase, are fast. The migration through the narrow access channel produces the detected current signal whose time course is controlled by the preceding deocclusion. Another conformational relaxation occurs before the second $\mathrm{Na}^{+}$ion is released, a fast process with an apparent rate constant in the order of
$10000 \mathrm{~s}^{-1}$ [48]. Two observations indicate a deocclusion step preceding diffusion of the second $\mathrm{Na}^{+}$out of the membrane domain: First, again a high activation energy of about $70 \mathrm{~kJ} / \mathrm{mol}$ is found for this partial reaction, and second, the electrogenicity of this release is reduced to a value of $10-20 \%$. Since it is known that the binding sites are not significantly dislocated during this reaction, a rearrangement of the $\alpha$ helices of the membrane domain has to be claimed in a way that they form a wide access channel being filled with water molecules [31, 54, 55]. This modification remodels the dielectric shape of the protein so that the ions in the binding sites are able to reach the polar aqueous phase within a short "dielectric" distance of $<0.2[31,48]$. This is in agreement with structural details revealed recently (see below). Thereafter, the release of the last $\mathrm{Na}^{+}$occurs with the similarly low dielectric coefficient, and with a rate so fast $\left(\geq 10^{6} \mathrm{~s}^{-1}\right)$ that it could not be resolved with the experimental techniques available.

$\mathbf{P}-\mathbf{E}_{\mathbf{2}} \rightarrow \mathbf{P}-\mathbf{E}_{2} \mathbf{K}_{2}$ : The ion-binding sites have a significantly lower affinity for protons in the $\mathrm{P}--\mathrm{E}_{2}$ conformation than in $\mathrm{E}_{1}$. Therefore, it is possible to produce a state without ions bound in the absence of $\mathrm{K}^{+}$, and the $\mathrm{K}^{+}$binding can be studies easily $[56,57]$. A sequential binding of $\mathrm{K}^{+}$(or $\mathrm{Rb}^{+}$) was found and described as "flickering gate" model which illustrates that the first $\mathrm{K}^{+}$binds (or is released) slowly while the second $\mathrm{K}^{+}$is able to exchange fast with the aqueous phase [56]. The equilibrium dissociation constants for the first and second $\mathrm{K}^{+}$differ by a factor of 5-6 at a below-millimolar level. This observation fits to the concept that, again, binding of the first $\mathrm{K}^{+}$is followed by a minor conformational modification of the membrane domain that affects the second binding site which is active only after the first is occupied and prevents release of the first ion bound. Besides $\mathrm{K}^{+}$congeneric monovalent cations may be transported such as

$$
\begin{aligned}
& \mathrm{Rb}^{+}, \mathrm{Cs}^{+}, \mathrm{Tl}^{+}, \mathrm{NH}_{4}^{+}, \mathrm{H}^{+} \text {or even } \mathrm{Na}^{+} . \\
& \mathbf{P}-\mathbf{E}_{\mathbf{2}} \mathbf{K}_{\mathbf{2}} \rightarrow \mathbf{A T P} \cdot \mathbf{E}_{\mathbf{2}}\left(\mathbf{K}_{\mathbf{2}}\right) \rightarrow \mathbf{K}_{\mathbf{2}} \mathbf{E}_{\mathbf{1}} \cdot \mathbf{A T P}: \text { Coordina- }
\end{aligned}
$$
tion of the second $\mathrm{K}^{+}$in the binding site of the $\mathrm{P}-\mathrm{E}_{2}$ state enables a subsequent spontaneous conformational rearrangement, leading to dephosphorylation of the enzyme and occlusion of the bound ions which produces the $\mathrm{E}_{2}\left(\mathrm{~K}_{2}\right)$ state [56]. The available experimental evidence indicates that dephosphorylation and occlusion go hand in hand. The occluded $\mathrm{E}_{2}\left(\mathrm{~K}_{2}\right)$ state is only transient and in the absence of ATP it decays with a rate constant of $0.1 \mathrm{~s}^{-1}$ (at $20^{\circ} \mathrm{C}$ ) by a conformation transition back to $\mathrm{E}_{1}$. In the presence of physiological concentrations of ATP the transition back to the $\mathrm{E}_{1}$ conformation is significantly accelerated. A detailed study of the electrogenicity of the $\mathrm{K}^{+}$-transporting half cycle revealed that apparently no charge is transported $[38,58,59]$. This observation has to be revisited in the light of more recent insights that the 
published experiments started at state $\mathrm{P}-\mathrm{E}_{2} \mathrm{~K}_{2}$, and therefore electrogenic binding of $\mathrm{K}^{+}$in $\mathrm{P}-\mathrm{E}_{2}$ has been missed. Occlusion of $\mathrm{K}^{+}$, ATP binding and the conformation transition as well as ion deocclusion occur without significant movements of the binding sites in the membrane domain. Release of $\mathrm{K}^{+}$to the cytoplasmic aqueous phase is actually a $\mathrm{K}^{+} / \mathrm{Na}^{+}$exchange or a $\mathrm{K}^{+} / \mathrm{H}^{+}$exchange in the absence of $\mathrm{Na}^{+}$(see above), and therefore also only apparently electroneutral.

\section{TRANSMEMBRANE CHANNEL FORMATION}

Before the achievements from studies of the various partial reactions around the pump cycle are assembled to a comprehensive pump mechanism and related to structural insights, another important property of the $\mathrm{Na}, \mathrm{K}-\mathrm{ATP}$ ase has to be introduced. When the sodium pump is treated with palytoxin, an extremely potent marine toxin, the protein is transformed into a nonselective cation channel [60-62]. Typical single-channel behavior was observed with opening and closing events and a conductance of 7-10 pS [63] (Fig. 6). The continuous opening and closing of the same channel shows that the protein is not frozen in the palytoxin-modified state. And the fast reversibility of this transformation suggested that no major conformational reorganization or even renaturation of the protein occurs but a simultaneous open state of both occlusion gates takes place [62]. This concept is supported by the fact that blockers of the access channels on both sides of the Na,K-ATPase are able to clog the ion pathway [64]. Recently, modifications of aminoacid side chains that affect the ion conductance through the palytoxin-modified Na,K-ATPase were used to identify the structure of the access channels of the intact ion pump [65, 66].

\section{STRUCTURAL DETAILS BY FACTS AND FEATURES}

After decades of building the mechanistic concepts of ion transport by the Na,K-ATPase purely on the basis of results from kinetic experiments, an exciting road to comprehension became available when first in 2000 the molecular structure of the Ca-ATPase of the sarcoplasmic reticulum (SERCA) in the $\mathrm{Ca}_{2} \mathrm{E}_{1}$ conformation was published with a resolution of $2.6 \AA$ [67]. In subsequent years a whole series of further conformations were published [68], and due to the close similarity of Ca-ATPase and $\mathrm{Na}$, K-ATPase numerous homology models were generated that allowed a first impression on structures of the Na-pump.

Eventually, at the end of 2007, the first X-ray crystal structure of the Na,K-ATPase with two bound $\mathrm{K}^{+}$ ions was published [69], and the congruence of a corresponding state, $\mathrm{E}_{2} \mathrm{MgF}_{4}^{2-}$, of both the $\mathrm{Na}, \mathrm{K}$ ATPase $\alpha$ subunit and SERCA is impressive, espe-
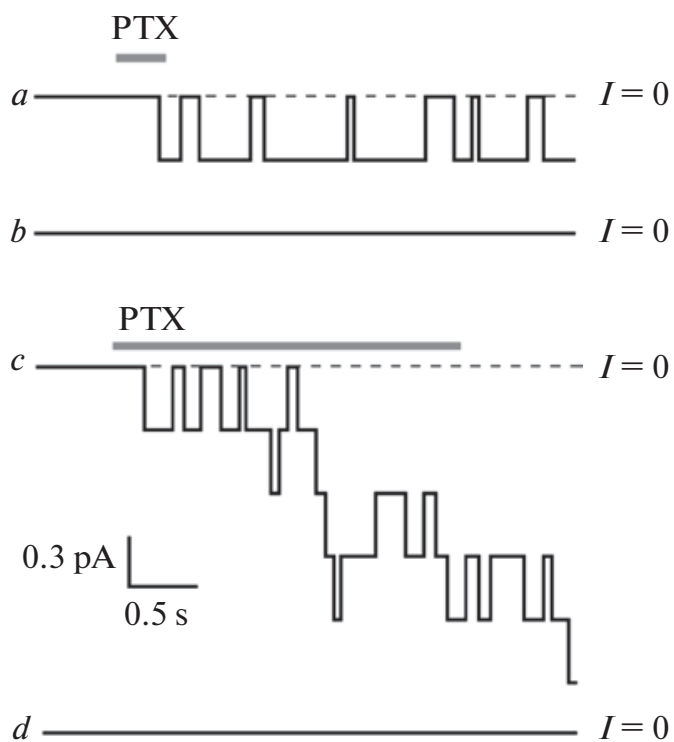

Fig. 6. Palytoxin (PTX) induced ion-channel behaviour of the Na,K-ATPase. Trace $a$ : When in the presence of $\mathrm{Na}^{+}$ and $\mathrm{Mg} \cdot \mathrm{ATP}$ a low concentration of PTX (25 pM) is administered, typical opening and closing of a cationselective channel is observed. Trace $b$ : After washout of PTX the channel events vanish and ion-pump activity is restored. Trace $c$ : Upon prolonged exposure to $25 \mathrm{pM}$ PTX more and more Na,K-ATPase molecules are transformed into ion channels. Trace $d$ : This behaviour can be abolished by high concentrations of ouabain. Figure adapted from [62].

cially with respect to the membrane domain. The cocrystallized $\beta$ and $\gamma$ subunits of the sodium pump from pig kidney are peripherally located, and do not modify significantly the structure of the $\alpha$ subunit (Fig. 7). Both rubidium (or potassium) ions occluded in the $\mathrm{Na}, \mathrm{K}-\mathrm{ATPa}$ e are coordinated by residues which exactly correspond to those that provide the oxygen ligands for $\mathrm{Ca}^{2+}$ binding in the $\mathrm{E}_{1}$ form of SERCA [69]. The ions occluded by SERCA in this $\mathrm{E}_{2} \mathrm{MgF}_{4}^{2-}$ conformation are $2-3 \mathrm{H}^{+}$ions which cannot be resolved by the $\mathrm{X}$-ray diffraction technique. The explicit agreement between both ion pumps adds a reassuring confidence to all the conclusions drawn so far from homology modelling of the Na,K-ATPase.

In the following years the $\mathrm{E}_{2} \mathrm{MgF}_{4}^{2-}$ structure was published with increased resolution [70], and subsequently further conformations became available with atomic resolution, $\mathrm{E}_{2}$ conformations with ouabain and other cardiac steroid-bound structures [71-73], as well as an $\mathrm{E}_{1}$ conformation with $3 \mathrm{Na}^{+}$bound $[74,75]$. The latter structures support strongly the concept that the $\mathrm{K}^{+}$binding site and two of the $\mathrm{Na}^{+}$binding sites are formed by the same moieties of the membrane domain of the $\alpha$ subunit between transmembrane helices TM4, TM5 and TM6. Minor rearrangements of the transmembrane helices lead to spatial restrictions 


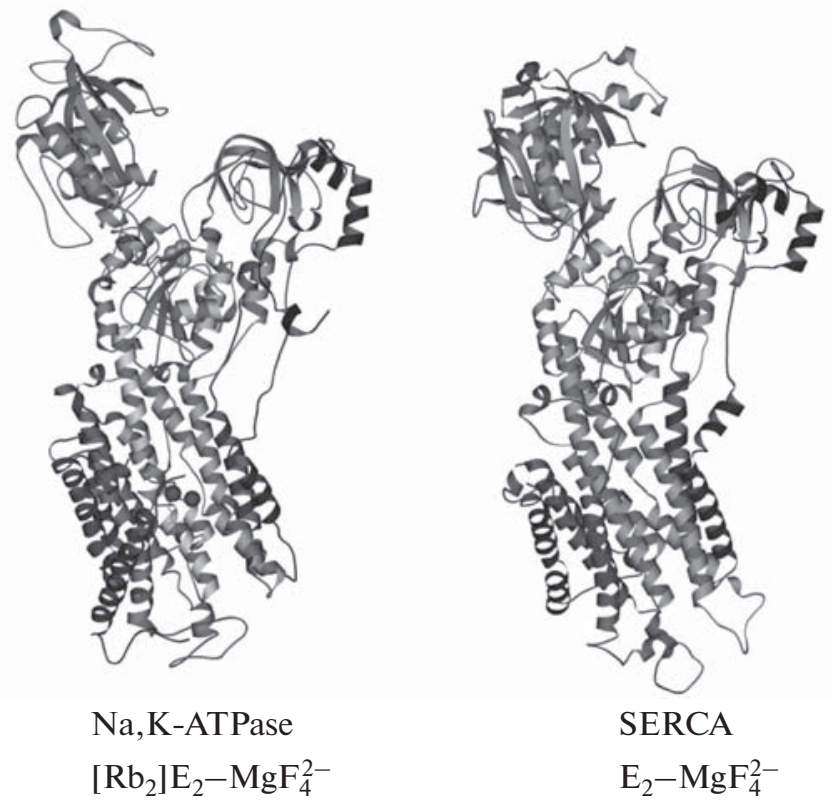

Fig. 7. Structures of the Na,K-ATPase and SERCA. Both ion pumps are shown in a corresponding conformation,

$\mathrm{E}_{2} \mathrm{MgF}_{4}^{2-}$. This conformation represents an ion-occluded form of both ion pumps [69]. In the Na,K-ATPase (PDB code $3 \mathrm{~B} 8 \mathrm{E}$ ) two bound $\mathrm{Rb}^{+}$ions are shown as grey spheres, the $2-3 \mathrm{H}^{+}$present in the SERCA (PDB code $1 \mathrm{WPG})$ are not visible. The $\beta$-ectodomain of the $\mathrm{Na}, \mathrm{K}-$ ATPase has been removed for clarity.

that define the different ion selectivities for $\mathrm{Na}^{+}$and $\mathrm{K}^{+}$in the $\mathrm{E}_{1}$ and $\mathrm{E}_{2}$ conformation. It was also found that a different number of water molecules is needed to coordinate either $\mathrm{K}^{+}$of $\mathrm{Na}^{+}$. The third $\mathrm{Na}^{+}$-binding site is a highly specific site that doesn't allow binding of other cations. Its location is assumed to be close to TM5, but slightly different in both published structures, either between TM5, TM6, TM8 [75] or between TM5, TM7, TM8 [74]. In both cases, however, the long TM5 helix that connects the membrane domain with the $\mathrm{P}$ domain is participating (and affected) by binding of the third $\mathrm{Na}^{+}$. This is important to establish communication with the ATP-binding site and enables, after complete occupation of all three ion sites by $\mathrm{Na}^{+}$, and only then, a propagation of the trigger to phosphorylation of the enzyme as next step in the pump cycle [45].

In the different states of the pump cycle the location of the binding sites does not change significantly. In the $\mathrm{E}_{1}$ conformation the cytoplasmic access pathway is proposed to take course between TM1,TM2,TM4 and TM6 in the shape of a narrow tunnel [67]. In the $\mathrm{P}-\mathrm{E}_{2}$ conformation, after release of the first $\mathrm{Na}^{+}$through a narrow well with high electrogenicity, a wide funnel-like pathway is formed that allows an easy exit to or entry from the extracellular aqueous phase. According to homology modeling from SERCA this pathway is formed by transmembrane helices M1 to M6 [76, 77], and its size is large enough to contain in the order of 60 water molecules [54]. The alternating opening and closure of both the cytoplasmic and extracellular access channels in the course of the pump cycle is achieved by significant rearrangements of transmembrane helices TM1 to TM6, which also modulate the binding affinities of the ion sites [78].

\section{THE ION-CHANNEL MODEL OF THE PUMP}

When the strands of experimental evidence from kinetics and structural investigations are brought together, a comprehensive mechanistic model can be presented. Interestingly, the emerging proposal was already introduced about 35 years ago by Peter Läuger on purely theoretical considerations [15, 79]. His idea was to construct an ion pump by two half channels (or "ion wells") which connect both aqueous phases with binding sites in the middle of the membrane domain of the pump. Access of the binding sites to either channels is controlled by two energy barriers whose structures are modified by an energy-supplying reaction. These barriers are synonymous with the gates introduced above. A strict barrier control avoids a shortcircuiting simultaneous opening of both gates. Therefore, occluded states during the pump cycle result straightforwardly from basic prerequisites.

The detailed structural insights presented above justify the concept of binding sites located inside the membrane domain in a position that is not significantly altered while the pump runs through its transport cycle. The existence of access channels on both sides of the binding sites is verified by the experiments on ion binding and release. All ion movements through the access channels have been proven to be electrogenic, although the contribution to the electrophysiologically detected currents depends on the varying cross section dimension. It is narrow on the cytoplasmic side, on the extracellular side it is narrow initially but widens up after the first $\mathrm{Na}^{+}$is released. The final proof of the existence of the channel structure was found by the action of palitoxin that overrides the strict barrier control, opens the cytoplasmic gate while the extracellular gate is already open and thus generates an end-to-end channel through the membrane domain of the $\mathrm{Na}, \mathrm{K}$-ATPase.

The position of the binding sites is fixed, therefore, ion binding and release are the only electrogenic partial reaction of the pump cycle. This principle was also shown for SERCA [80] and the gastric H,K-ATPase [43]. A recent study demonstrated that the access channels are impenetrable on the side where the gate is closed, i.e. the external access in $\mathrm{E}_{1}$ and the cytoplasmic access in $\mathrm{P}-\mathrm{E}_{2}$ [32]. 


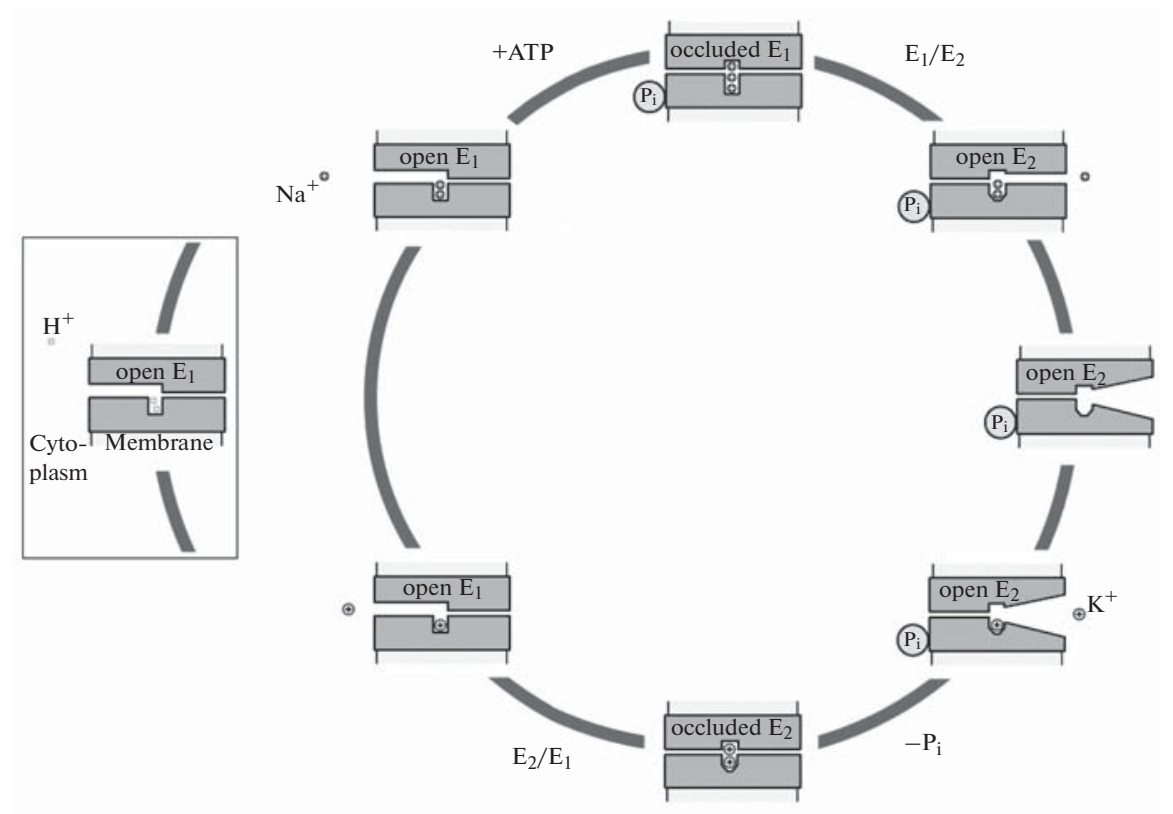

Fig. 8. Schematic representation of the condition of the Na,K-ATPase membrane domain (cytoplasmic domain at the left end of the structure is omitted for simplicity) while running through the pump cycle. Access to the binding sites in the center of the membrane domain is afforded by alternately opened half-channels, from the cytoplasm in the $\mathrm{E}_{1}$ conformation and from the extracellular side in the $\mathrm{P}-\mathrm{E}_{2}$ conformation. These open states are separated by occluded states that prevent a counterproductive passive transport through a transmembrane channel. In the $\mathrm{P}-\mathrm{E}_{2}$ state the narrow access channel widens up after release of the first $\mathrm{Na}^{+}$. In contrast to the $\mathrm{P}-\mathrm{E}_{2}$ conformation, in $\mathrm{E}_{1}$ the binding sites are always occupied in the physiological $\mathrm{pH}$ range. In the absence of other monovalent cations about two protons are occupying both unselective cation binding sites.

Taking all these data and conclusions together, the status quo of the ion-transport mechanism of the $\mathrm{Na}, \mathrm{K}-\mathrm{ATPase}$ can be summarized by the model presented in Fig. 8. The membrane domain forms two dynamic half-channels that are selective for monovalent cations and connected by a central binding moiety. These half-channels are opened alternately, in the $\mathrm{E}_{1}$ conformation on the cytoplasmic side, in the $\mathrm{P}-\mathrm{E}_{2}$ conformation to the extracellular side. The ordered sequence of ion binding through the opened access channel, ion occlusion in the binding sites, and ion release through the other, in turn opened access channel is performed for both transported ion species. The channel opening and closing as well as ion specificity of the binding sites is controlled by the three cytoplasmic domains ( $\mathrm{N}, \mathrm{P}$, and $\mathrm{A})$ of the protein which perform the enzymatic activity and advance the pump cycle by phosphorylation from ATP and subsequent dephosphorylation.

\section{UNRESOLVED ISSUES}

Although there is convincing evidence that Peter Läuger's proposal of the ion-transport mechanism of the $\mathrm{Na}, \mathrm{K}-\mathrm{ATPase}$ is an appropriate description of the molecular process, there are still some awkward questions left which may turn out to be hard nuts to crack. It is a missing link to explain in detail how the cytoplasmic domain is triggered to undergo its phosphory- lation. Other questions are how exactly do the ions thread their way between the ten alpha helices that form the transmembrane domain of the $\mathrm{Na}, \mathrm{K}$ ATPase, and what makes sure that there is no detectable ion movement through the "closed" access channels? And last but not least, the mechanism of energy conversion by the Na,K-ATPase (or any other P-type ATPase) is completely unresolved. The free energy obtained by ATP hydrolysis is transferred to the enzyme via phosphorylation. But how is it spent to drive the uphill ion transport since the analysis of the energetics does not reveal a "power stroke" in the course of the pump cycle?

\section{CONCLUSIONS}

So far what the molecular mechanism of the energy transduction of the Gibbs Free Energy from ATP hydrolysis into the electrochemical potential gradient of $\mathrm{Na}^{+}$and $\mathrm{K}^{+}$ions across the cell membrane is not understood. Analyses of structure-function relation provide, however, a reliable insight into the molecular processes procuring the ion translocation. Based on an abundance of kinetical experiments with various biophysical and biochemical methods lead to the introduction of a channel model of the Na,K-ATPase with strictly controlled gates or barriers. The alternating access to the ion-binding sites in the middle of the enzyme's membrane domain, together with modu- 
lated ion-binding affinities, generates an effective $\mathrm{Na}^{+}$ removal from the cytoplasm and a $\mathrm{K}^{+}$accumulation inside the cell. This so-called primary active ion transport occurs under physiological conditions (at $37^{\circ} \mathrm{C}$ ) with typical turnover rates in the order of $100 \mathrm{~s}^{-1}$ and an energy yield of about $70 \%$.

\section{REFERENCES}

1. Skou, J.C., Biochim. Biophys. Acta, 1957, vol. 23, p. 394.

2. Skou, J.C., Biosci. Rep., 1998, vol. 18, p. 155.

3. Palmgren, M.G. and Nissen, P., Annu. Rev. Biophys., 2011, vol. 40, p. 243.

4. Geering, K., Curr. Opin. Nephrol. Hypertens., 2008, vol. 17, p. 526.

1 5. Garty, H. and Karlish, S.J., Annu. Rev. Physiol., 2006, vol. 68, p. 431.

6. Geering, K., Am. J. Physiol Renal Physiol, 2006, vol. 290, pp. F241-F250.

7. Dostanic-Larson, I., van Huysse, J.W., Lorenz, J.N., and Lingrel, J.B., Proc. Natl. Acad. Sci. USA, 2005, vol. 102 , p. 15845.

8. Schoner, W. and Scheiner-Bobis, G., Am. J. Cardiovasc. Drugs, 2007, vol. 7, p. 173.

9. Albers, R.W., Ann. Rev. Biochem., 1967, vol. 36, p. 727.

10. Post, R.L., Hegyvary, C., and Kume, S., J. Biol. Chem., 1972, vol. 247, p. 6530.

11. Apell, H.-J., Rev. Physiol. Biochem. Pharmacol., 2003, vol. 150, p. 1 .

12. Damnjanovic, B., Weber, A., Potschies, M., et al., Biochemistry, 2013, vol. 52, p. 5563.

13. Sweadner, K.J. and Donnet, C., Biochem. J., 2001, vol. 356, p. 685 .

14. Läuger, P., Electrogenic Ion Pumps, Sunderland, MA, 1991.

15. Läuger, P., Biochim. Biophys. Acta, 1979, vol. 552, p. 143.

16. Läuger, P. and Apell, H.-J., Eur. Biophys. J., 1986, vol. 13, p. 309.

17. Hill, T.L., Free Energy Transduction and Biochemical Cycle Kinetics, New York, 1989.

18. Heyse, S., Wuddel, I., Apell, H.-J., and Stürmer, W., J. Gen. Physiol., 1994, vol. 104, p. 197.

19. Borlinghaus, R., Apell, H.-J., and Läuger, P., J. Membr. Biol., 1987, vol. 97, p. 161.

20. Fendler, K., Grell, E., Haubs, M., and Bamberg, E., EMBO J., 1985, vol. 4, p. 3079.

21. Sokolov, V.S., Ayuan, A.G., and Apell, H.-J., Eur. Biophys. J., 2001, vol. 30, p. 515.

22. Sokolov, V.S., Apell, H.-J., Corrie, J.E., and Trentham, D.R., Biophys. J., 1998, vol. 74, p. 2285.

23. Apell, H.-J. and Sokolov, V.S., Pumps, Channels and Transporters, Methods of Functional Analysis, Hoboken, NJ, 2015, p. 23.

24. Apell, H.-J., Borlinghaus, R., and Läuger, P., J. Membr. Biol., 1987, vol. 97, p. 179.

25. Borlinghaus, R. and Apell, H.-J., Biochim. Biophys. Acta, 1988, vol. 939, p. 197.
26. Jørgensen, P.L., Meth. Enzymol., 1974, vol. 32, p. 277.

27. Kaplan, J.H., Forbush, B., III, and Hoffman, J.F., Biochem., 1978, vol. 17, p. 1929.

28. Domaszewicz, W. and Apell, H.-J., FEBS Lett., 1999, vol. 458 , p. 241.

29. Pintschovius, J. and Fendler, K., Biophys. J., 1999, vol. 76, p. 814.

30. Bartolommei, G., Devaux, N., Tadini-Buoninsegni, F., et al., Biophys. J., 2008, vol. 95, p. 1813.

31. Wuddel, I. and Apell, H.-J., Biophys. J., 1995, vol. 69, p. 909.

32. Sokolov, V.S., Scherbakov, A.A., Lenz, A.A., et al., Biochemistry (Moscow) Suppl. Ser. A: Membr. Cell Biol., 2008, vol. 2, p. 161.

33. Karlish, S.J.D. and Yates, D.W., Biochim. Biophys. Acta, 1978, vol. 527, p. 115.

34. Apell, H.-J. and Bersch, B., Biochim. Biophys. Acta, 1987, vol. 903, p. 480.

35. Clarke, R.J., Apell, H.-J., and Läuger, P., Biochim. Biophys. Acta, 1989, vol. 981, p. 326.

36. Cornelius, F., Biochim. Biophys. Acta, 1991, vol. 1071, p. 19.

37. Apell, H.-J. and Damnjanovic, B., P-Type ATPases, Methods and Protocols, New York, 2016, p. 127.

38. Stürmer, W., Bühler, R., Apell, H.-J., and Läuger, P., J. Membr. Biol., 1991, vol. 121, p. 163.

39. Bühler, R., Stürmer, W., Apell, H.-J., and Läuger, P., J. Membr. Biol., 1991, vol. 121, p. 141.

40. Pedersen, M., Roudna, M., Beutner, S., et al., J. Membr. Biol., 2002, vol. 185, p. 221.

41. Apell, H.-J. and Diller, A., FEBS Lett., 2002, vol. 532, p. 198.

42. Fibich, A., Janko, K., and Apell, H.J., Biophys. J., 2007, vol. 93, p. 3092.

43. Diller, A., Vagin, O., Sachs, G., and Apell, H.-J., Biophys. J., 2005, vol. 88, p. 3348.

44. Goldshlegger, R., Karlish, S.J., Rephaeli, A., and Stein, W.D., J. Physiol (Lond.), 1987, vol. 387, p. 331.

45. Schneeberger, A. and Apell, H.-J., J. Membr. Biol., 1999, vol. 168, p. 221.

46. Schneeberger, A. and Apell, H.-J., J. Membr. Biol., 2001, vol. 179, p. 263.

47. Inesi, G., J. Biol. Chem., 1987, vol. 262, p. 16338.

48. Holmgren, M., Wagg, J., Bezanilla, F., et al., Nature, 2000, vol. 403, p. 898.

49. de Weer, P., Gadsby, D.C., and Rakowski, R.F., The $\mathrm{Na}^{+}, \mathrm{K}^{+}$-pump, Part A: Molecular Aspects, New York, 1988, p. 421.

50. Hilgemann, D.W., Science, 1994, vol. 263, p. 1429.

51. Nakao, M. and Gadsby, D.C., J. Gen. Physiol., 1989, vol. 94, p. 539.

52. Sagar, A. and Rakowski, R.F., J. Gen. Physiol., 1994, vol. 103 , p. 869.

53. Friedrich, T. and Nagel, G., Biophys. J., 1997, vol. 73, p. 186.

54. Gradinaru, R.V. and Apell, H.J., Biochemistry, 2015, vol. 54 , p. 2508.

55. Gadsby, D.C., Bezanilla, F., Rakowski, R.F., et al., Nat. Commun., 2012, vol. 3, p. 669. 
56. Forbush, B., III, Prog. Clin. Biol. Res. A, 1988, vol. 268, p. 229.

57. Bühler, R. and Apell, H.-J., J. Membr. Biol., 1995, vol. 145 , p. 165.

58. Goldshlegger, R., Karlish, S.J., Rephaeli, A., and Stein, W.D., J. Physiol., 1987, vol. 387, p. 331.

59. Bahinski, A., Nakao, M., and Gadsby, D.C., Proc. Natl. Acad. Sci. USA, 1988, vol. 85, p. 3412.

60. Tosteson, M.T., Bignami, G.S., Scriven, D.R.L., et al., Biochim. Biophys. Acta, 1994, vol. 1191, p. 371.

61. Wang, X. and Horisberger, J.-D., FEBS Lett., 1997, vol. 409 , p. 391.

62. Artigas, P. and Gadsby, D.C., Proc. Natl. Acad. Sci. $U S A, 2003$, vol. 100 , p. 501.

63. Artigas, P. and Gadsby, D.C., J. Gen. Physiol, 2004, vol. 123 , p. 357.

64. Harmel, N. and Apell, H.J., J. Gen. Physiol., 2006, vol. 128 , p. 103.

65. Reyes, N. and Gadsby, D.C., Nature, 2006, vol. 443, p. 470.

66. Takeuchi, A., Reyes, N., Artigas, P., and Gadsby, D.C., Nature, 2008, vol. 456, p. 413.

67. Toyoshima, C., Nakasako, M., Nomura, H., and Ogawa, H., Nature, 2000, vol. 405, p. 647.

68. Moller, J.V., Olesen, C., Winther, A.M., and Nissen, P., Q. Rev. Biophys., 2010, vol. 43, p. 501.
69. Morth, J.P., Pedersen, B.P., Toustrup-Jensen, M.S., et al., Nature, 2007, vol. 450, p. 1043.

70. Shinoda, T., Ogawa, H., Cornelius, F., and Toyoshima, C., Nature, 2009, vol. 459, p. 446.

71. Ogawa, H., Shinoda, T., Cornelius, F., and Toyoshima, C., Proc. Natl. Acad. Sci. USA, 2009, vol. 106, p. 13742.

72. Laursen, M., Yatime, L., Nissen, P., and Fedosova, N.U., Proc. Natl. Acad. Sci. USA, 2013, vol. 110, p. 10958.

73. Laursen, M., Gregersen, J.L., Yatime, L., et al., Proc. Natl. Acad. Sci. USA, 2015, vol. 112, p. 1755.

74. Nyblom, M., Poulsen, H., Gourdon, P., et al., Science, 2013, vol. 342, p. 123.

75. Kanai, R., Ogawa, H., Vilsen, B., et al., Nature, 2013, vol. 502, p. 201.

76. Olesen, C., Picard, M., Winther, A.M., et al., Nature, 2007, vol. 450, p. 1036.

77. Toyoshima, C., Norimatsu, Y., Iwasawa, S., et al., Proc. Natl. Acad. Sci. USA, 2007, vol. 104, p. 19831.

78. Toyoshima, C. and Nomura, H., Nature, 2002, vol. 418 , p. 605.

79. Läuger, P., Biochim. Biophys. Acta, 1984, vol. 779, p. 307.

80. Butscher, C., Roudna, M., and Apell, H.-J., J. Membr. Biol., 1999, vol. 168, p. 169. 